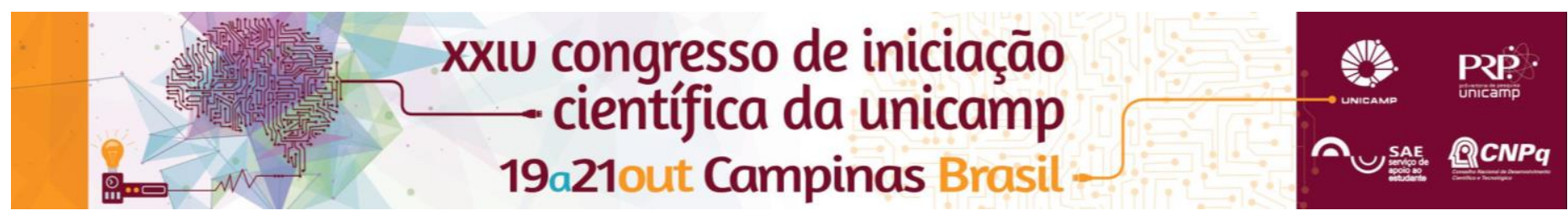

\title{
Avaliação do processo de adsorção de metais tóxicos por partículas produzidas pelos biomateriais sericina e alginato
}

\author{
Viviane H. Meinerz*, Thiago L. Silva, Melissa G. A. Vieira.
}

\section{Resumo}

O objetivo deste trabalho é avaliar o processo de adsorção de metais tóxicos e nobres por partículas produzidas por sericina (Ser), alginato (Alg) e polietilenoglicol diglicídico (PEG). Diagramas de especiação metálica em função do pH, o estudo de afinidade metálica pelos metais nobres e tóxicos e o estudo cinético da adsorção de prata pelas partículas foram realizados. Os resultados indicaram que as partículas apresentaram afinidade satisfatória pelo íon prata (63\%) e os modelos cinéticos se ajustaram aos dados adequadamente.

\section{Palavras-chave:}

sericina, alginato, prata, adsorção.

\section{Introdução}

A sericina é uma proteína hidrossolúvel, descartada no processamento do casulo do bicho da seda, e o alginato é um polissacarídeo extraído de algas marrons, muito abundantes na costa brasileira. Ambos são polímeros que habilitam seu uso na produção de biomateriais, como as partículas empregadas em processos de adsorção[1]. O objetivo deste estudo é avaliar a remoção de metais pelas partículas produzidas a partir da blenda entre sericina, alginato e polietilenoglicol.

\section{Resultados e Discussão}

Oito tipos de partícula foram preparados a partir da blenda entre Ser $(2,5 \% \mathrm{~m} / \mathrm{V})$, Alg $(2 \% \mathrm{~m} / \mathrm{V})$ na presença ou ausência de PEG $(0,2 \mathrm{~g}$ de $\mathrm{PEG} / \mathrm{g}$ Ser) em sua composição. As blendas foram gotejadas em solução aquosa e a alcoólica (etanol) de $\mathrm{CaCl}_{2}$ e $\mathrm{Ca}\left(\mathrm{NO}_{3}\right)_{2}$. A partícula produzida com Ser/Alg/PEG (gotej. em solução aquosa de $\left.\mathrm{Ca}\left(\mathrm{NO}_{3}\right)_{2}\right)$ apresentou os melhores resultados. As porcentagens de redução dos íons $\mathrm{Au}, \mathrm{Pt}$, $\mathrm{Pd}, \mathrm{Ag}, \mathrm{Cu}, \mathrm{Ni}, \mathrm{Cd}, \mathrm{Pb}$ e $\mathrm{Cr}$ após o teste de afinidade são apresentados na Tabela 1.

Tabela 1. Porcentagem de remoção (\%) dos metais após o teste de afinidade.

\begin{tabular}{cccccc}
\hline $\mathbf{P d}$ & $\mathbf{P t}$ & $\mathbf{A u}$ & \multicolumn{2}{c}{$\mathbf{A g}$} \\
$88,9 \%$ & $71,6 \%$ & $99,7 \%$ & $63,4 \%$ & \\
\hline $\mathbf{C d}$ & $\mathbf{N i}$ & $\mathbf{P b}$ & $\mathbf{C r}$ & $\mathbf{C u}$ \\
$79,6 \%$ & $23,7 \%$ & $82,8 \%$ & $73,7 \%$ & $73,0 \%$
\end{tabular}

Como a prata é um metal nobre de maior uso industrial e em função do resultado satisfatório alcançado (63,4 \%), em comparação com os dados da literatura ${ }^{[2]}$, efetuou-se o estudo cinético de adsorção com este íon.

Pela Figura 1, o diagrama de especiação metálica mostra que a prata se encontra solúvel até $\mathrm{pH} \sim 9$, ou seja, em pH menores que 9 não há precipitação de $\mathrm{Ag}^{+}$.

O estudo cinético foi feito, protegidos da luz, em três concentrações (6 g de partículas para $600 \mathrm{~mL}$ de solução, $\mathrm{pH} \sim 5,24 \mathrm{~h}$ ). Foram avaliados 4 modelos cinéticos: modelo de pseudoprimeira (PsP), pseudossegunda (PsS), difusão intrapartícula (DIP) e modelo de Boyd (MB). Os resultados indicaram que os modelos PsP, PsS e DIP ajustaram-se aos dados experimentais apresentando altos valores de $\mathrm{R}^{2}$. O MB não se ajustou satisfatoriamente aos dados. Os resultados para PsP e PsS são mostrados na Figura 2.

Figura 1. Diagrama de especiação metálica da prata.

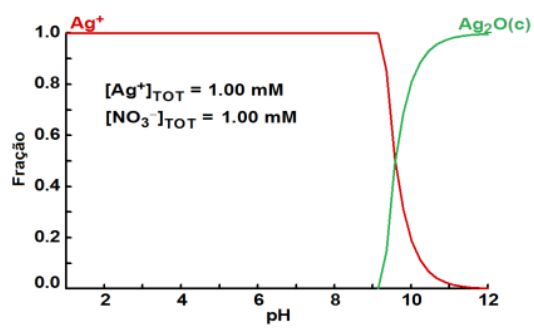

Figura 2. Curvas cinéticas obtidas e as respectivas modelagens de pseudoprimeira e pseudossegunda ordens.

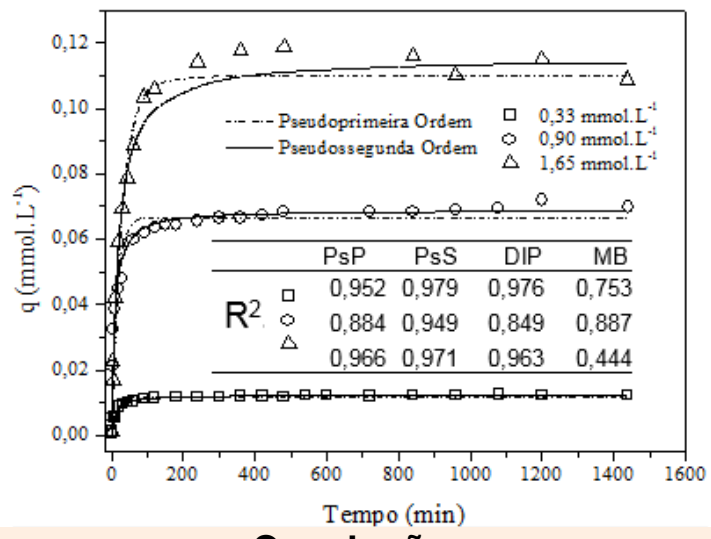

Conclusões

Pela afinidade metálica, a partícula com sericina, alginato, agente reticulante (PEG), gotejada em solução aquosa de nitrato de cálcio é a melhor dentre as analisadas. A prata foi escolhida para estudo cinético, mostrando bons ajustes para modelo de pseudoprimeira e pseudossegunda ordens e de difusão intrapartícula.

\section{Agradecimentos}

Agradecimentos ao PIBIC pela concessão da bolsa de IC e ao CNPq pelo apoio financeiro.

${ }_{1}^{1}$ Silva, T. L. et al., Biosorption study of copper and zinc by particles produced from silk sericin e alginate blend: evaluation of blend proportion and thermal cross-linking process in particles production, J. Clean Prod. , 1-9, 2015.

2 Cantuária, M. L. Remoção de prata iônica monovalente por adsorção em argila bentonítica. Dissertação (Mestrado em Engenharia química). Universidade Estadual de Campinas, Campinas, 2014. 